\title{
FLUIDYNAMIC EFFECTS ON THE DEPOSITION OF ALUMINA PARTICLES AT THE UPPER TUNDISH NOZZLE*
}

\author{
Enif Gutiérrez Guerrero ${ }^{1}$ \\ Saúl García Hernández² \\ José de Jesús Barreto Sandova ${ }^{3}$ \\ Beatriz Adriana Martínez Lara ${ }^{4}$
}

\begin{abstract}
Inclusion deposition is still a standing problem in the continuous casting of steel since the deposition of alumina inclusions inside the SEN affects the productivity and the product quality. The present work studies the factors involved in the inclusion deposition at the nozzle and the effects of inertial, gravitational, buoyant, pressure gradient, and Saffman forces on the inclusion trajectories. The results show that the inclusions reaching the nozzle, only $30 \%$ get deposited along its walls mainly at the Upper Tundish Nozzle (UTN). This area of higher deposition is identified close to a low static pressure and a high turbulent kinetic energy dissipation zones where the effects of the gravitational and buoyant forces do not promote a significant inclusion radial movement since these are aligned with the direction of the flow stream lines. In contrast, in this zone, the Saffman force shows an important effect on the deposited inclusions, slowing down the inclusions in the vertical axis and increasing their radial movement.
\end{abstract}

Keywords: SEN clogging; Low static pressure zone; Inclusion force balance.

1 Ph. D., Professor, Metallurgical Graduate Center, TecNM - Instituto Tecnologico de Morelia, Morelia, Michoacan, Mexico.

2 Ph. D., Professor, Metallurgical Graduate Center, TecNM - Instituto Tecnologico de Morelia, Morelia, Michoacan, Mexico.

3 Ph. D., Professor, Metallurgical Graduate Center, TecNM - Instituto Tecnologico de Morelia, Morelia, Michoacan, Mexico.

4 M. Sc., Professor, Department of Biochemical Engineering, TecNM - Instituto Tecnologico de Morelia, Morelia, Michoacan, Mexico. 


\section{INTRODUCTION}

The use of tundish flow control devices and argon curtains has been widely employed to reduce the amount of non-metallic inclusion in the final product. Nevertheless, a high percentage of inclusions are not removed in the tundish reaching the nozzle where some of them are no uniformly deposit at typical zones of the nozzle [1-8]. For aluminum killed steel, alumina inclusions are the most common cluster material, which is produced during the deoxidation, from the interaction of refractory material and molten steel [1-14], and finally from the re-oxidation of steel. This inclusion deposition induces a problem known as clogging phenomenon which has been studied for many researchers. Some authors have studied the variables affecting the inclusion trajectory, focusing on the forces balance. Sasai et al. [15] found that the drag force is the dominant force. Yuan et al. [16] studied the SEN Clogging and Su-zhou et al. [17] studied the inclusion removal near the mold top surface, both considering the overall effect of drag, gravity, buoyant, and Saffman forces on the inclusion trajectory, without analysing the individual relevancy of each force on the inclusion deposition. Trying to reduce the clogging, argon injection through the nozzle wall has been used and recently, it has been injected at the stopper rod tip [18-23]. Despite all these research works, the disruptive clogging phenomenon is still present nowadays; consequently, the main objective of the present research work is to explain the phenomenon of the non-uniform inclusion deposition at the nozzle wall and analyze the individual dynamic effect of inertial, gravitational, buoyant, pressure gradient, and Saffman forces on the deposited inclusion trajectories inside the upper tundish nozzle. To achieve this, a three dimensional mathematical model was developed for a coupled tundish-mould system.

\section{MATERIAL AND METHODS}

A three dimensional mathematical model was developed based on the Navier-Stokes equations, the standard $\mathrm{k}-\varepsilon$ model, and the Lagrangian discrete phase model. To solve the set of equations several assumptions were considered:

The fluid flowing into the coupled tundish-mould system was assumed to have incompressible Newtonian behaviour. The system was modelled considering unsteady state and isothermal conditions. Turbulent and laminar flows coexist in the tundish; however, only laminar flow is present close to solid walls. Therefore, typical no slip conditions were applied at all solid surfaces. Standard wall functions were used at nodes close to any wall. The inclusions were considered as spherical solid particles with alumina properties, non-interaction among them. For the sizes $(1,10$, 20, 30 and 60 micrometers), 40 trials were carry out adding 50 inclusion at the ladle shroud until 2000 inclusions were reached. Because it was difficult to include the results of too many inclusion sizes, in the study of the effect of the forces only three sizes were considered representing the range of 1 to 60 micrometers sizes $(5,30$ and 60 micrometers). The inclusions were added along a line of $6 \mathrm{~mm}$ at the centre of the ladle shroud top surface. It was considered only one deposition condition along all nozzle walls. If an inclusion touches the wall, it is deposited. The drawing and meshing of the 1:1 scale system were performed using GAMBIT®. 
The governing equations were discretized using the finite volume technique and solved through the commercial ANSYS-FLUENT® package, considering the computational segregated-iterative method. The non-linear URANS equations were linearized using the implicit approach. The discretization was performed using the First Order Upwind scheme. The Body Force Weighted scheme was used for pressure interpolation. Based on the simultaneous update of the dependent variables, the algorithm pressure-velocity coupling used here is the approach known as SIMPLEC. The system was considered in Cartesian coordinates, and the gravity force was considered to act over the negative $y$ coordinate. The operating pressure was the atmospheric pressure equals to $101325 \mathrm{~Pa}$. Inlet and outlet were defined as a velocity-inlet condition and calculated using the employed volumetric flow. A constant time step equal to $t=0.01$ s was considered for the solver.

Since the simulation was time-dependent, the system was simulated for an unsteady state period of 300 seconds; during the last minute of simulation, the flow profiles remain almost constant allowing the consideration that steady state was reached, and at this point, the present flow analysis was carried out using instantaneous numerical data.

\section{RESULTS AND DISCUSSION}

Once the inclusions are feed in the ladle shroud, only $30 \%$ of the inclusions reaching the nozzle gets deposited along the nozzle wall. The mean percentage distribution of the deposited inclusion is shown in Figure 1, where the upper tundish nozzle zone exhibits the higher amount of deposited inclusions for all sizes.

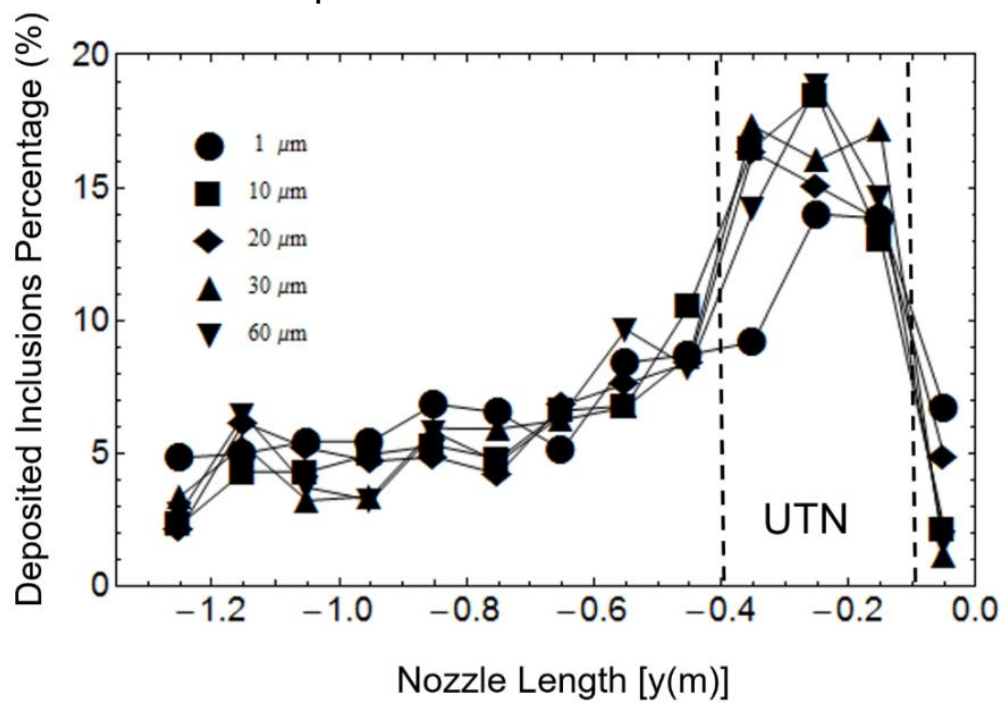

Figure 1. Mean percentage distribution of the deposited inclusions along the nozzle, for inclusion sizes of of $1 \mu \mathrm{m} 10 \mu \mathrm{m}, 20 \mu \mathrm{m}, 30 \mu \mathrm{m}$ and $60 \mu \mathrm{m}$

To understand the reason of this inhomogeneous deposition, the velocity profile along the nozzle for the flow is shown in Figure 2. The results show a velocity increment at the entry of the UTN at $0<y<-0.1 \mathrm{~m}$ and consequently, this is the zone with a low percentage of deposited inclusions, later remains almost constant along $-0.1<y<-0.4 \mathrm{~m}$ indicating that the flow acceleration is close to zero, which favours the inclusion deposition as is corroborated by the deposition highest percentage in this zone. Then for $y<-0.4 \mathrm{~m}$, the flow velocity increases linearly with the SEN length. 


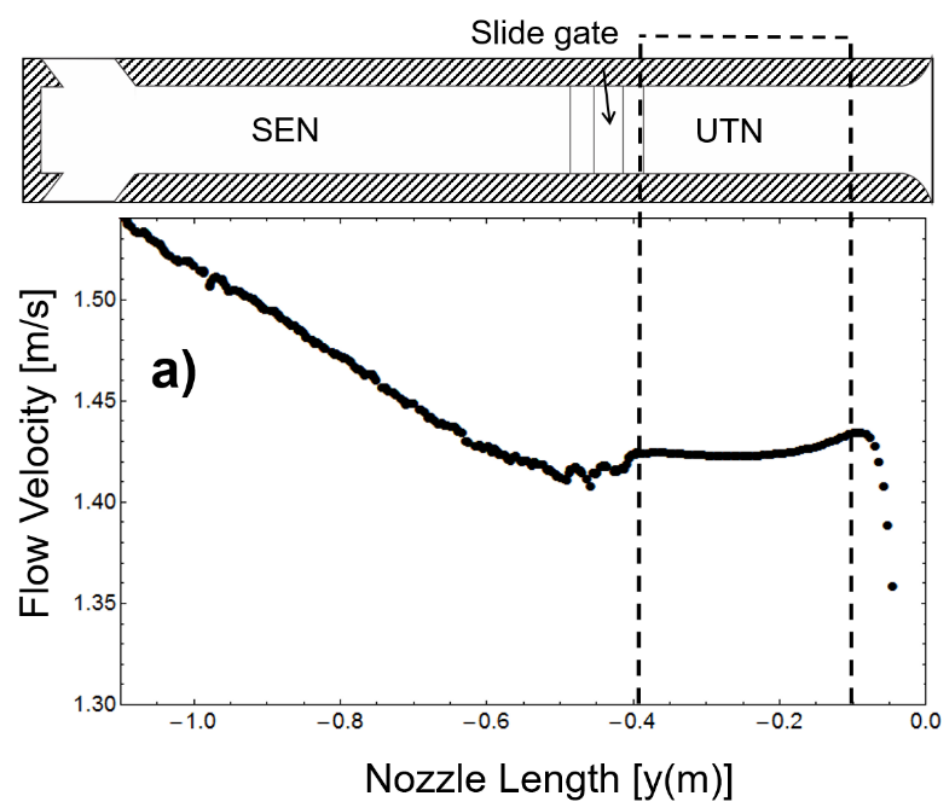

Figure 2. Mean fluid velocity profile along the nozzle

The highest deposition zone is also related to a decrement of the static pressure (Figure 3a), an increment in the dynamic pressure (Figure 3b), an increment of the turbulent kinetic energy (Figure 3c), and an increase on the vorticity (Figure 3d). The decrement of the static pressure occurs because of the flow fluctuant velocity increment, which can be inferred from the growth of the dynamic pressure and the turbulent kinetic energy, inducing disequilibrium on the mechanical energy balance. This unbalance can be identified as mechanical energy dissipation related to an increase on the vorticity since the flow losses energy while is swirling. However is still unclear why some inclusions get deposited and some others do not, being necessary to analyse the forces acting on the inclusion along its trajectory. For this, inclusions of 20, 30 and 60 microns and the following forces were selected: pressure gradient, buoyant, gravity, and Saffman forces. Since the CFD software does not deliver these forces individually, it was necessary to calculate them analytically. To present a better result comparison, in the following figures, the behaviour of the deposited inclusions is presented at the left side and to the right side those that reach the mould. All the figures shows the inclusion trajectories respect to the nozzle radius, where $\left(x_{0}, z_{0}\right)$ is at the centre of the nozzle, and the maximum radius equal to $0.0375 \mathrm{~m}$ is at the wall. The further analysis will be focused on a representative sample considering two of each studied sizes. 

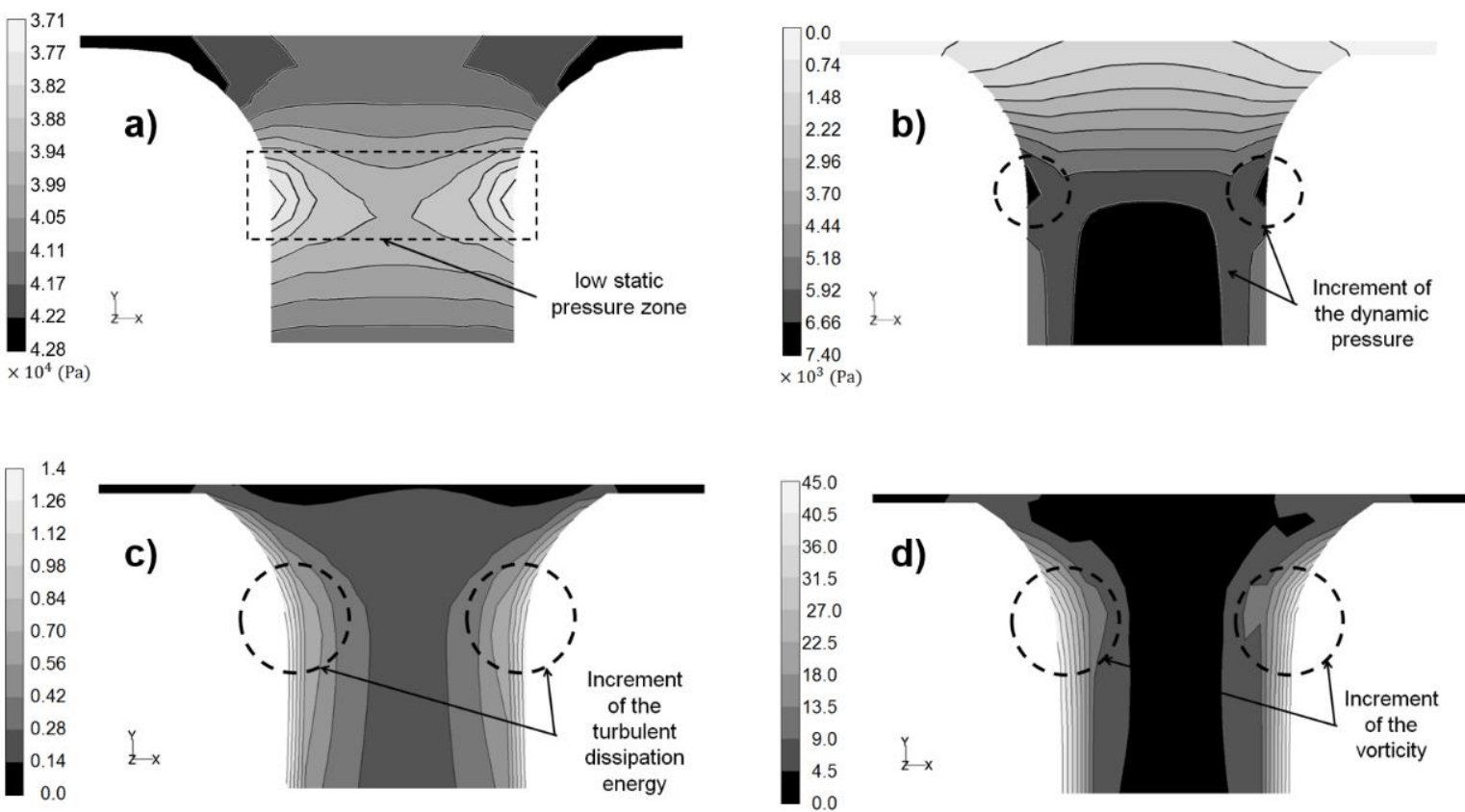

Figure 3. Contours at the central symmetrical plane of the upper tundish nozzle a) Static pressure $(\mathrm{Pa}), \mathrm{b})$ Dynamic Pressure (Pa), c) Turbulent dissipation energy $\left(\mathrm{m}^{2} / \mathrm{s}^{3}\right)$ and d) Vorticity $(1 / \mathrm{s})$.

\subsection{Pressure Gradient Force Effect}

This force depends on the inclusion velocity and the velocity changes of the main flow, considering the steel density and the alumina density. Figure 4 shows the force at ten points of the inclusion trajectory inside the low static pressure zone which is in the range of $1-100 \mathrm{~N} / \mathrm{kg}$. For the deposited inclusions, the pressure gradient force has the effect to redirect the inclusions towards the minimum value of the low static pressure zone $(y \approx-0.05 \mathrm{~m})$ and therefore to the nozzle wall. Even some inclusions that do not get deposited can also be disturbed by the attraction effect towards this zone Figure $4 \mathrm{~d}$ ), g), k) and I). In order to find out if this attraction effect remains on the deposited inclusions, a similar analysis was carried out at the zones where the inclusions were stuck see Figure 5. It is important to notice that in contrast to the values obtained close to the minimum value of the low pressure zone, the force magnitude in $x$ and $z$ at the deposition zone is one order of magnitude smaller. Consequently, in this zone the pressure gradient force does not promote a radial movement; therefore, it does not contribute in a determinant manner to the adhesion phenomenon. Due to the above discussion, it is necessary to analyse others important forces on the inclusion motion as the Buoyant and gravitational forces. 
Deposited Inclusions
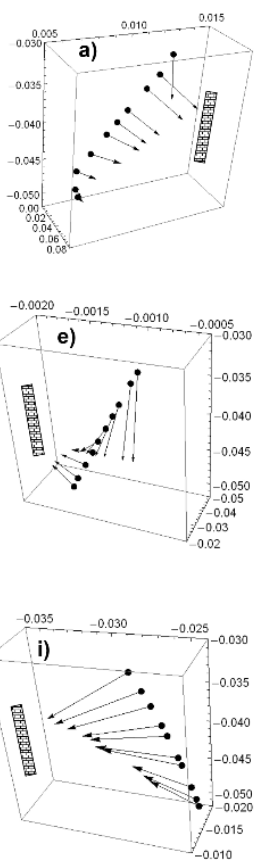

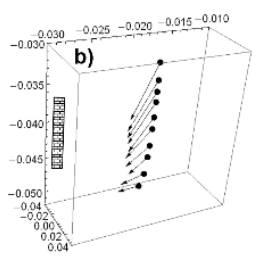

Non Deposited Inclusions
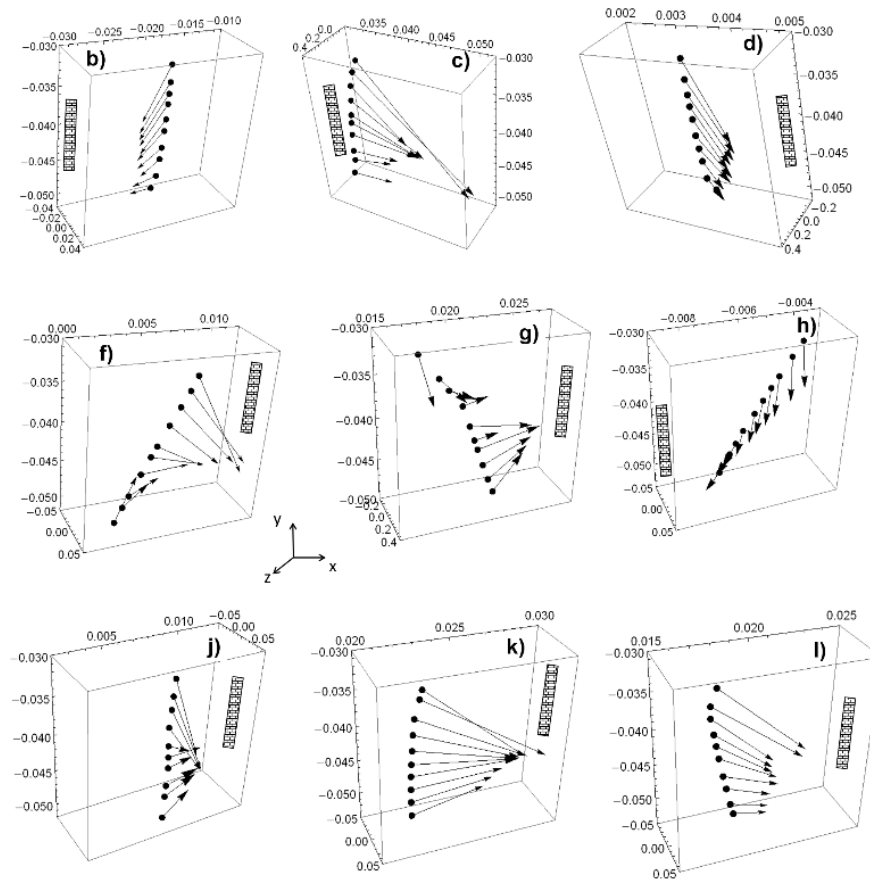

Schematic representation of the wall

Figure 4. Three dimensional gradient pressure force per unit mass scaled by a factor " $s$ " equal to $2\left(10^{-4}\right)$, at the low static pressure zone, [a) - d)] $5 \mu \mathrm{m}$, [e) - h)] $30 \mu \mathrm{m}$, and [i) - I)] 60 $\mu m$.

\section{Deposited Inclusions}
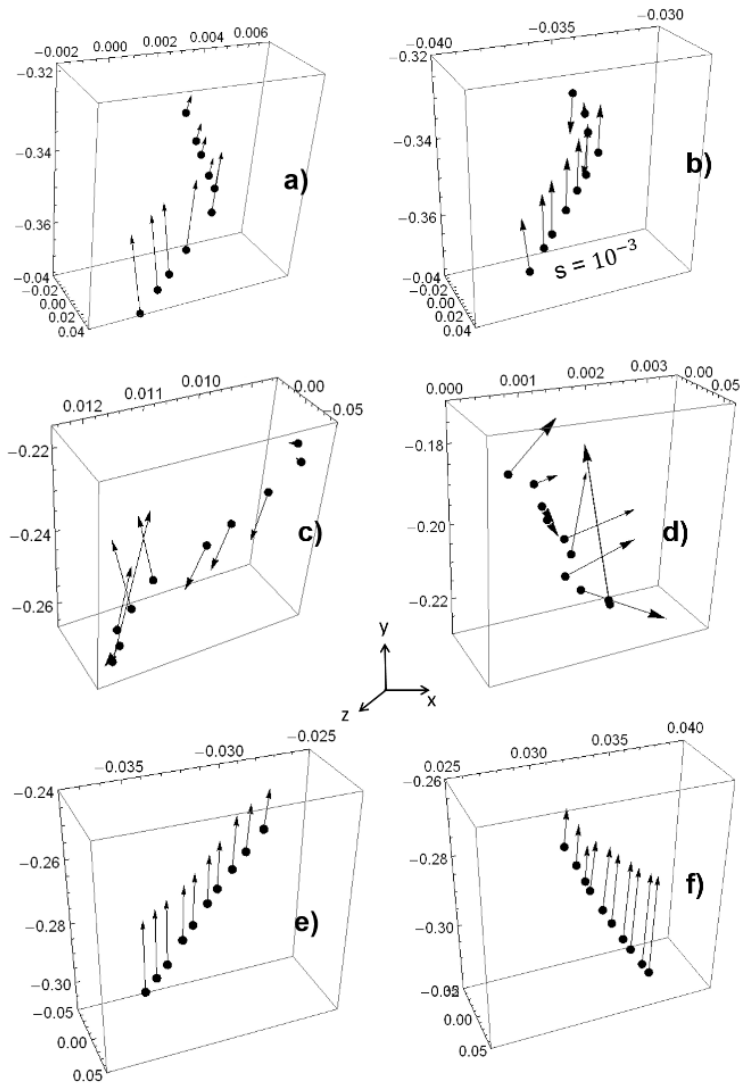

Figure 5. Three dimensional gradient pressure force per unit mass scaled by a factor "s" equal to $\left(10^{-3}\right)$, at the deposited inclusion zone, [a), b)] $5 \mu \mathrm{m}$, [c), d)] $30 \mu \mathrm{m}$, and [e), f)] $60 \mu \mathrm{m}$. 


\subsection{Buoyant and gravitational force effect}

Considering that at the adhesion zone the stream lines are in the same direction as gravity, the gravitational and buoyant forces effects are only on the vertical axis. The resultant magnitude of the buoyant and gravitational forces per unit mass is calculated using $F_{B}+F_{G}=\frac{\left(\rho-\rho_{p}\right) g}{\rho_{p}}$, where a constant value equal to $9.54 \mathrm{~N} / \mathrm{kg}$ is obtained and it is opposite to the gravity direction. Evidently, the consideration of these forces is not determinative to the inclusion deposition phenomenon. Therefore, there must be other forces acting radially at the deposition zone. Considering this, the Saffman force will be analysed in the following section.
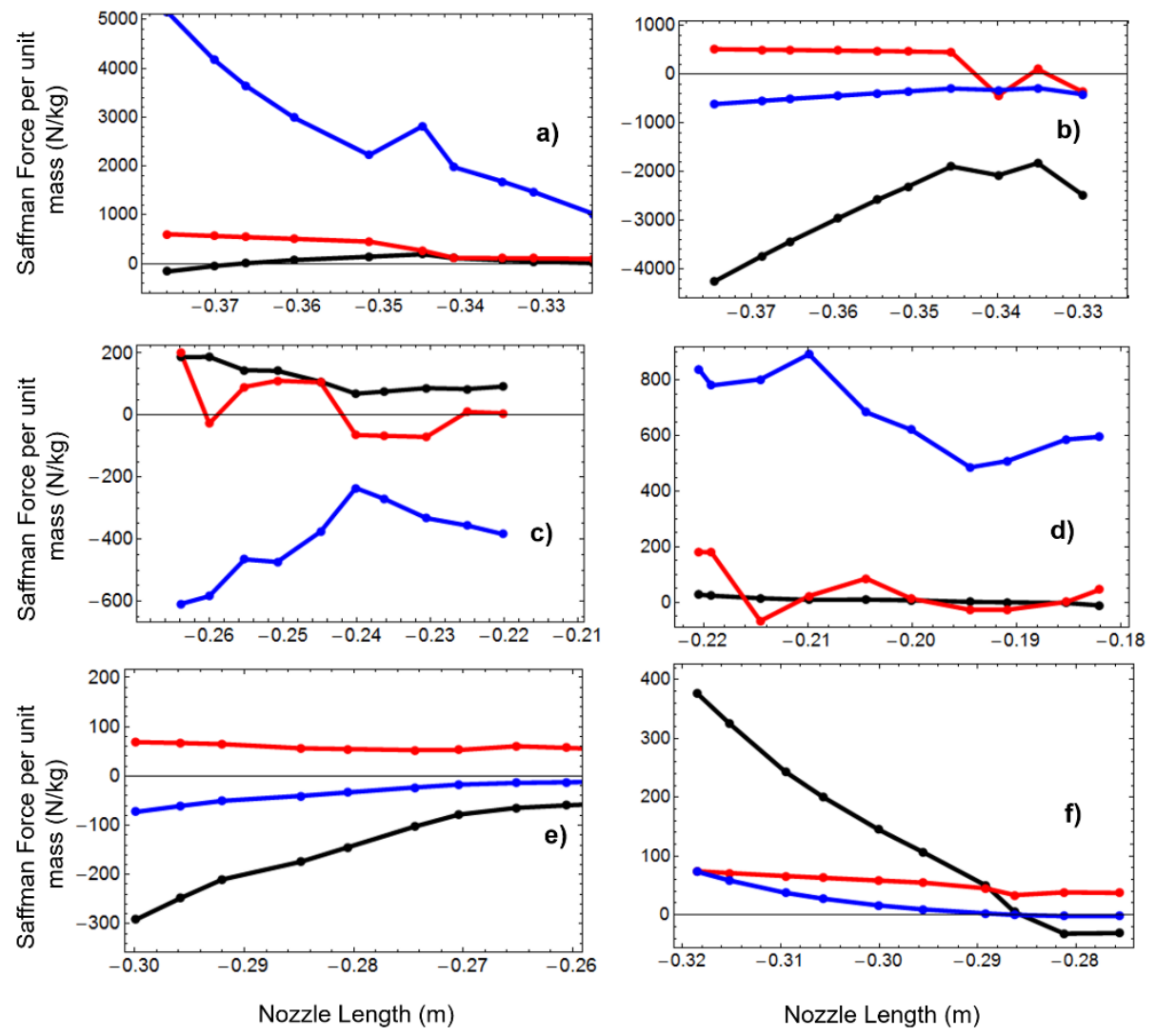

$$
--F_{S x}--F_{S y}--F_{S z}
$$

Figure 6. Saffman force components at the deposition zone, [a), b)] $5 \mu m$, [c), d)] $30 \mu m$, and [e), f)] 60 $\mu m$.

\subsection{Saffman force effect}

The Saffman force becomes dominant when the velocity gradients are high $\left(v_{\text {in }}>\right.$ $\left.v_{s t}\right)$, since promotes radial and lifting effects on the inclusions close to the walls.

Figure 6 shows the Saffman force in the three directions, for all the deposited inclusion at the adhesion zone, showing a significant increment in $x$ and $z$, being positive in $y$ direction Consequently, it can be established that the Saffman force has a slowdown effect on the inclusion respect to $y$ direction and induce an inclusion movement in the radial sense. In order to determine whether this radial effect induces an inclusion to get deposited, a comparison between the Saffman force profiles (Figure 6) and the trajectory of the deposited inclusion (Figure 7) was carried out. It is 
evident that for the component where the Saffman force presents the highest magnitude, it is the same component where the inclusion tends to move, independently of its size, and the inclusion gets deposited with this tendency. From the above discussion, it can be determined that the Saffman force has the highest effect on the inclusion trajectory, increasing its tendency to move radially and inducing its deposition.
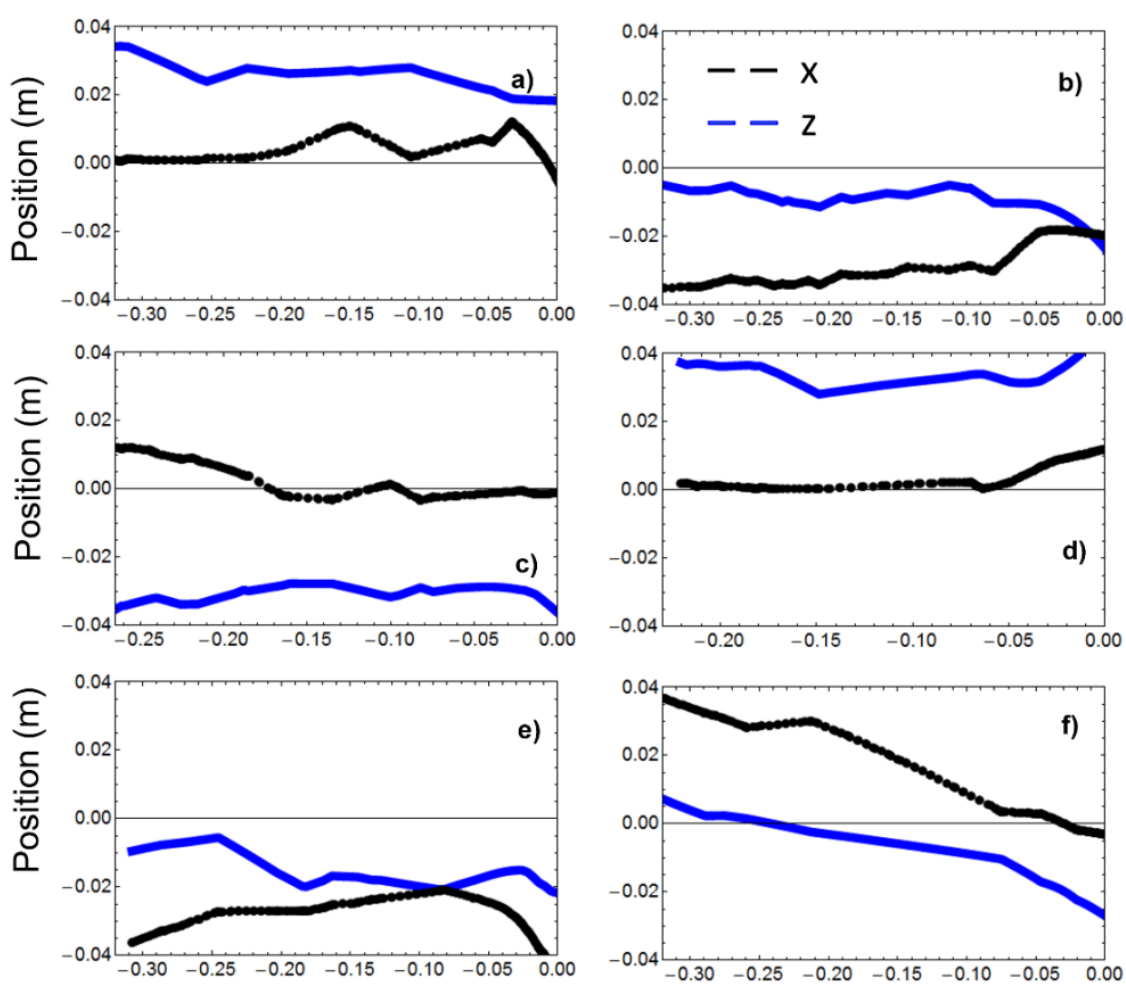

Nozzle Lenght $(m)$
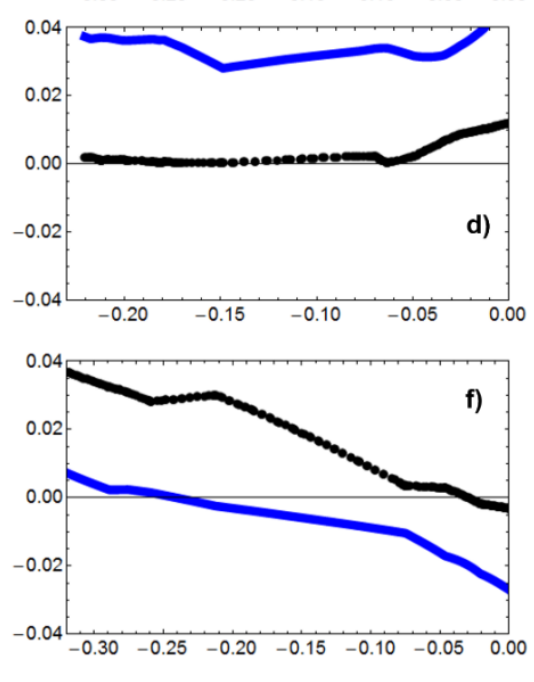

Nozzle Lenght $(m)$

Figure 7. Inclusions positions at $x$ and $z$ along their trajectories [a), b)] $5 \mu m$, [c), d)] $30 \mu m$, and [e), f)] $60 \mu \mathrm{m}$.

\section{CONCLUSION}

1. The inclusions get highly deposited at the the upper tundish nozzle just after a zone with the following characteristics: low static pressure zone, an increment in the dynamic pressure, an increment of the turbulent kinetic energy, and an increase on the vorticity.

2. Gravitational and buoyant forces do not contribute to the inclusion deposition to the nozzle wall since its combined effect is only on the flow direction.

3. The Saffman force is much higher than the rest of the analysed forces for all inclusions sizes.

4. At the deposition zone, the Saffman force shows two noticeable effects on the inclusions trajectories: it tends to slow down the inclusion in the vertical axis and increases significantly its radial movement.

\section{Acknowledgments}

The authors give thanks to the institutions TecNM-ITM, PRODEP and SNI for their permanent support to the Academic Research Group on Simulation of Materials Processing and Fluidynamics. 


\section{REFERENCES}

1 R. B. Snow and J. A. Shea. Mechanism of erosion of nozzles in open-hearth ladles. J. Am. Ceram Soc. 1949; 32:187-194.

2 S. N. Singh. Mechanism of alumina buildup in tundish nozzles during continuous casting of aluminum-killed steels. Metall. Mater. Trans. 1974; 5:2165-2178.

3 Y. Miki, H. Kitaoka, T. Sakuraya, and T. Fujii. Mechanism for separating inclusions from molten steel stirred with a rotating electro-magnetic field. ISIJ Int. 1992; 32:142-149.

4 T. B. Braun, J. F. Elliott, and M. C. Flemings. The clustering of alumina inclusions. Metall. Mater. Trans. B. 1979; 10B:171-184.

5 L. Zhang and B. G. Thomas. State of the art in the control of inclusions during steel ingot casting. Metall. Mater. Trans. B. 2006; 37B:733-761.

6 S. Abdelaziz, G. Megahed, I. El-Mahallawi, and H. Ahmed. Control of Ca addition for improved cleanness of low C, Al killed steel. Ironmaking Steelmaking. 2009; 36:432441.

7 Z. Deng, M. Zhu, B. Zhong, and D. Sichen. Attachment of liquid calcium aluminate inclusions on inner wall of submerged entry nozzle during continuous casting of calcium-treated steel. ISIJ Int. 2014; 54:2813-2820.

8 L. Brinkmeyer and S. D. Melville. Factors affecting cleanliness of continuously cast steel. Ironmaking Steelmaking. 1995; 22:502-507.

9 T. Bolender, H. Jacobi, M. Weinberg, and K. Wünnenberg. Mixing and oxide cleanness in sequence casting of heats of differing compositions. Steel Res. Int. 2007, 78:31-38.

10 F. Tehovnik, J. Burja, B. Arh, and M. Knap. Submerged entry nozzle clogging during continuous casting of Al-killed steel. Metalurgija. 2015; 54:371-374.

11 K. Sasai, Y. Mizukami, and H. Yamamura. Reaction mechanism between alumina graphite immersion nozzle and low carbon steel. Tetsu-to-Hagané. 1993; 79:10671074.

12 Y. Fukuda, Y. Ueshima, and S. Mizoguchi. Mechanism of alumina deposition on alumina graphite immersion nozzle in continuous caster. ISIJ Int. 1992; 32:164-168.

13 K. Sasai and Y. Mizukami. Reaction mechanism between alumina graphite immersion nozzle and low carbon steel. ISIJ Int. 1994; 34:802-809.

14 Y. Vermeulen, B. Coletti, B. Blanpain, P. Wollants, and J. Vleugels. Material evaluation to prevent nozzle clogging during continuous casting of Al killed steels. ISIJ Int. 2002; 42:1234-1240.

15 K. Sasai and Y. Mizukami. Mechanism of alumina adhesion to continuous caster nozzle with reoxidation of molten steel. ISIJ Int. 2001; 41:1331-1339.

16 Q. Yuan, B. G. Thomas and S. P. Vanka. Study of transient flow and particle transport in continuous steel caster molds: Part II. Particle transport. Metall. Mater. Trans. B. 2004; 35B:703-714.

17 W. Su-zhou, Z. Jiong-ming, and L. Zhi-zheng. Mathematic model of SEN clogging during continuous casting of steel. J. of Iron and Steel Res. Int. 2010; 17:6-9.

18 R. Liu and B. G. Thomas. Model of gas flow through porous refractory applied to an upper tundish nozzle. Metall. Mater. Trans. B. (2015); 46B:388-405.

19 K. Jin, B. G. Thomas, R. Liu, S. P. Vanka and X. M. Ruan. Simulation and validation of two-phase turbulent flow and particle transport in continuous casting of steel slabs. IOP Conf. Series: Material Science and Engineering. 2015; 84:1-8.

$20 \mathrm{H}$. Bai and B. G. Thomas. Effects of clogging, argon injection, and continuous casting conditions on flow and air aspiration in submerged entry nozzles. Metall. Mater. Trans. B. 2001; 32B:707-722.

21 M. Javurek, M. Thumfard, and R. Wincor. Investigations on flow pattern and pressure inside SEN below stopper rod. Steel Research Int. 2010; 81: 668-674.

22 K. Timmel, N. Shevchenko, M. Röder, M. Anderhuber, P. Gardin, S. Eckert, and G. Gerbeth. Visualization of liquid metal two-phase flows in a physical model of the continuous casting process of steel. Metall. Mater. Trans. B. 2014; 46B:700-710. 
23 Z. Deng, M. Zhu, B. Zhong, and D. Sichen. Attachment of liquid calcium aluminate inclusions on inner wall of submerged entry nozzle during continuous casting of calcium-treated steel. ISIJ Int. 2014; 54:2813-2820. 